\title{
Association of COVID-19 and other viral infections with interstitial lung diseases, pulmonary fibrosis, and pulmonary hypertension: A narrative review
}

\author{
Elham Atabati ${ }^{1,2}$, Amir Dehghani-Samani ${ }^{3,4}$, Sayyed Gholamreza Mortazavimoghaddam ${ }^{1}$
}

\begin{abstract}
E Atabati, A Dehghani-Samani, S G Mortazavimoghaddam. Association of COVID-19 and other viral infections with interstitial lung diseases, pulmonary fibrosis, and pulmonary hypertension: A narrative review. Can J Respir Ther 2020;56:70-78. doi: 10.29390/cjrt-2020-021.

Background: Interstitial lung diseases (ILDs) include a broad range of diffuse parenchymal lung disorders and are characterized by diffuse parenchymal lung abnormalities leading to irreversible fibrosis. ILDs are correlated with the occurrence of pulmonary fibrosis (PF), which generally also results in pulmonary hypertension $(\mathrm{PH})$. Interferons, secreted in larger amounts during viral infections, are an important possible risk factor contributing to this outcome.

Aims: In this narrative review, the role of 10 different viral infections on the generation/development of ILDs and their outcomes are described in detail. The aim of this review is to determine the probable risk that COVID-19 and other viral infections pose in the post-infection development of ILDs, PF, and PH.

Methods: Searches in PubMed (Medline), Google Scholar, Web of Science (ISI, Researcher ID, Publons), ResearchGate, Scopus, and secondary sources yielded 134 studies. After exclusion criteria, 92 studies containing the terms "Coronavirus" (COVID-19), "Interstitial Lung Diseases," "Pulmonary Fibrosis," "Pulmonary Hypertension" and "viral infections" were selected for inclusion. Selected articles were read with a focus on the roles of the 10 commonly studied viral infections on generation/intensification of ILDs and classified according to their dominant effect on the respiratory system, with a focus on each infection's effects on parenchyma of the lungs and generation and/or intensification of ILDs.

Results: This review found that ILDs, PF, and PH can occur after a COVID-19 viral infection. Similar results are also seen in post-infection cases of other viral infections, including Epstein-Barr virus, Cytomegalovirus, Human herpesvirus-8, adenovirus, Hepatitis C, Torque-Teno (Transfusion-Transmitted) Virus, Human Immunodeficiency Virus, Severe Acute Respiratory Syndrome, and Middle East Respiratory Syndrome.

Conclusion: Results of current studies show probable possibility for generation and/or intensification of ILDs in COVID-19 infected patients like other studied viruses. Studies on determination of the actual prevalence of ILD, PF and PH in post-COVID-19 infected patients, follow-up studies on the prevention of ILDs in recovered COVID-19 patients, and meta-analyzed studies on pulmonary outcomes of pandemic corona viruses are strongly recommended as topics for future studies.
\end{abstract}

Key Words: COVID-19; interstitial lung diseases; pulmonary fibrosis; pulmonary hypertension

\section{INTRODUCTION}

Interstitial lung diseases (ILDs) or diffuse parenchymal lung diseases clinically present with dyspnea, restrictive pulmonary function, and impaired gas exchange. They include a broad range of diffuse parenchymal lung disorders, which are characterized by widespread and heterogeneous parenchymal lung abnormalities and can lead to irreversible fibrosis [1]. ILDs are categorized as having certain known etiologies (non-idiopathic) and unknown etiologies (idiopathic) [2], as listed in Figure 1 [3] and Figure 2 [2], according to the classification of different authors. Most infections have known mechanisms in their actions. However, some of the viral infections, perhaps because their mechanism in ILD generation and/or augmentation has been unclear or uncertain, are categorized in the idiopathic interstitial pneumonia group with unknown causes [1-3].

ILDs are correlated with the occurrence of pulmonary fibrosis (PF), which generally results in pulmonary hypertension (PH) [1]. PF is a heterogeneous pulmonary disease with a high mortality rate characterized by the progressive and irreversible destruction of lung architecture caused by scar formation. This can ultimately lead to organ malfunction, disruption of gas exchange, and death from respiratory failure [4]. PF is resistant to treatment and has limited therapeutic options. Patients diagnosed with idiopathic pulmonary fibrosis (IPF), a particularly severe form of pulmonary fibrosis with unknown etiology, have a life expectancy of 2-6 years [5].

There are several similarities in the radiographic presentation of idiopathic ILDs especially cryptogenic organizing pneumonia, acute interstitial pneumonia, nonspecific interstitial pneumonia, and other forms of ILDs that are related to collagen vascular diseases and viral infections such as coronavirus (COVID-19) and influenza that may be mistaken with each other $[6,7]$; however, that is beyond the scope of this review and data are still emerging.

${ }^{1}$ Department of Internal Medicine, Faculty of Medicine, Birjand University of Medical Sciences and Health Services, Birjand, Iran

${ }^{2}$ Clinical Research Development, Vali' Asr Hospital, Birjand University of Medical Sciences and Health Services, Birjand, Iran

${ }^{3}$ Faculty of Medicine, Birjand University of Medical Sciences and Health Services, Birjand, Iran

${ }^{4}$ Department of Clinical Sciences, Faculty of Veterinary Medicine, Shahrekord University, Shahrekord, Iran

Correspondence: Amir Dehghani-Samani, Faculty of Medicine, Birjand University of Medical Sciences and Health Services, Birjand, Iran. Tel: +985632395000,

Fax:+985632430076, E-mail: amirds2008@gmail.com

Published online at https://www.cjrt.ca on 26 November 2020

This open-access article is distributed under the terms of the Creative Commons Attribution Non-Commercial License (CC BY-NC) (http:// creativecommons.org/licenses/by-nc/4.0/), which permits reuse, distribution and reproduction of the article, provided that the original work is properly cited and the reuse is restricted to noncommercial purposes. For commercial reuse, contact editor@csrt.com 


\section{FIGURE 1}

Categorization of ILDs according to their causes.

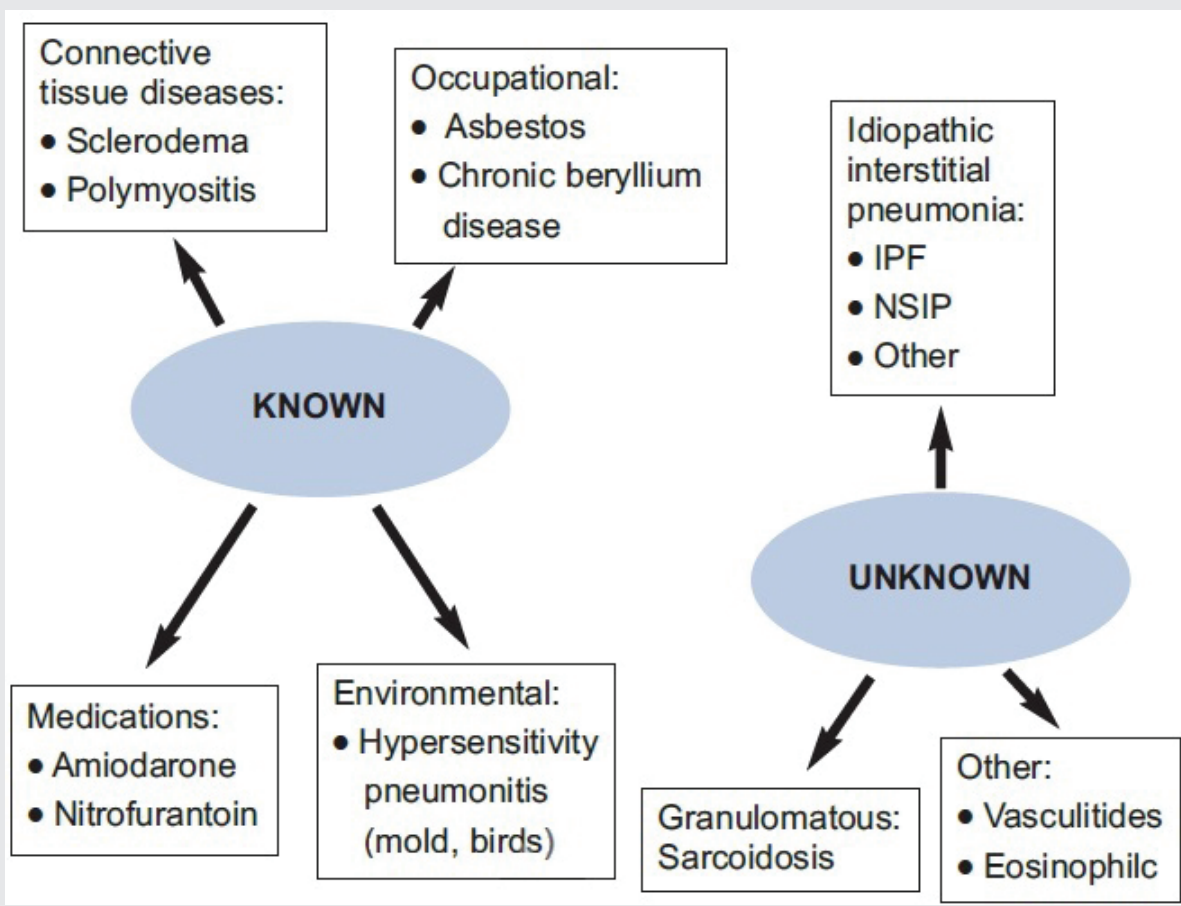

Note: IPF, Idiopathic pulmonary fibrosis; NSIP, nonspecific interstitial pneumonia [3].

\section{FIGURE 2}

Other categorization of ILDs according to their causes [2].

\section{Diffuse Parenchymal Lung Disease}

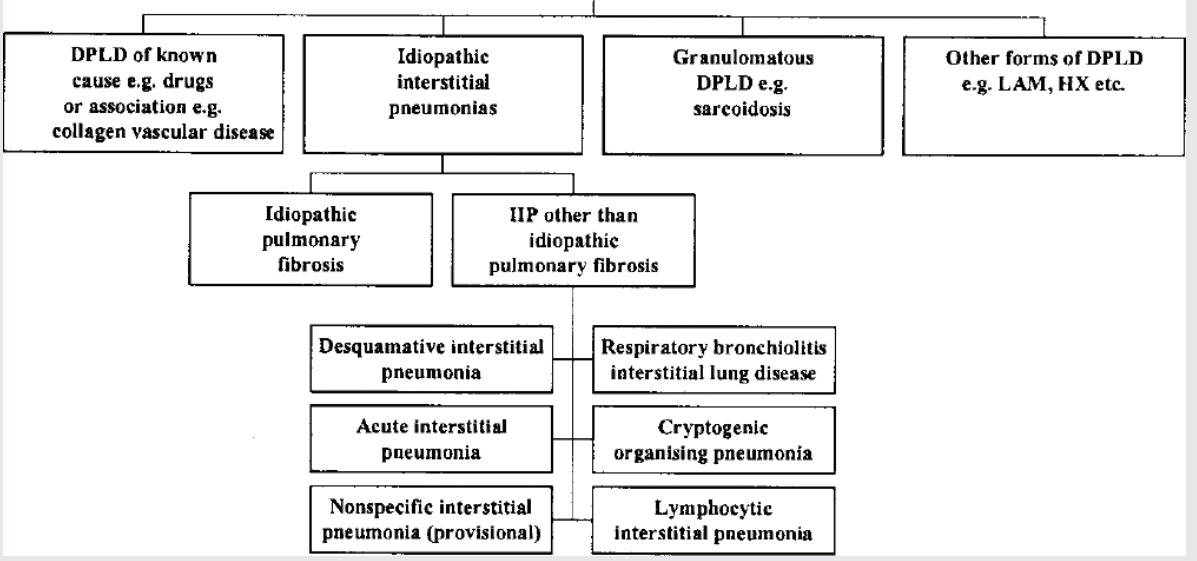

Note: ILD, interstitial lung diseases; DPLD, diffuse parenchymal lung diseases.

The aim of this review is to determine the probable risk that COVID-19 and other viral infections pose in the development of ILDs, $\mathrm{PF}$, and $\mathrm{PH}$ as important post-infection outcomes. Ten different viral infections that can lead to the generation of ILDs are described in detail for: COVID-19, Epstein-Barr virus (EBV), Cytomegalovirus, Human herpesvirus-8 (HHV-8), adenovirus, Hepatitis C, Torque-Teno
(Transfusion-Transmitted) Virus, Human Immunodeficiency Virus (HIV), Severe Acute Respiratory Syndrome and Middle East Respiratory Syndrome. The intent of this review is to draw attention to these important potential outcomes of COVID-19 and other infections with the hope that it leads to action and further studies to prevent against these probable outcomes of ILD, PF, and PH in recovered patients. 


\section{METHODS}

Between December 2019 and April 2020 (from the first emergence of COVID-19 until the start of the study), searches of Google Scholar, PubMed, Scopus, and other indexing websites were conducted using the keywords "Coronavirus" (COVID-19), "Interstitial Lung Diseases," "Pulmonary Fibrosis," "Pulmonary Hypertension" and "viral infection." This search generated 134 full-text related articles, of which 42 articles were omitted as repeats or because of unrelated subject matter. The final 92 articles that were selected included studies published between January 1972 and April 2020. Old studies were not omitted because they were closely related to primary reports about ILDs and published data for their mechanisms, and they were related to first reports of viral infections roles on the generation/development of ILDs. Downloaded/purchased full-text articles were read with a focus on the roles of the 10 commonly studied viral infections on generation/intensification of ILDs; they were classified according to their dominant effect on the respiratory system, with a focus on each infection's effects on parenchyma of the lungs and generation and/or intensification of ILDs.

\section{Etiology and role of interferon}

According to Wynn [4], there are six mechanisms involved in the development of PF, including:

1) Mechanisms with a role in the regulation of proliferation, activation, and differentiation of epithelial cells and collagen-secreting fibroblasts/myofibroblasts;

2) The role of pre-inflammatory and inflammatory mediators like Tumor necrosis factor (TNF), Interleukin 1 (IL-1), Interleukin 17-A (IL-17A), etc., in PF;

3) The role of oxidative stress mediators like reactive oxygen species and NADPH oxidase (NOX), regulation by type 2 helper $\mathrm{T}$ cells (Th2) responses, IL-13, Interferon gamma (IFN-Y), Interleukin 4 (IL-4), and Interleukin 5 (IL-5). Chemokines recruit leukocytes and fibroblasts such as Chemokine C-C motif ligand 18 (CCL18), Chemokine C-C motif ligand 2 (CCL2), Chemokine C-C motif ligand 6 (CCL6), C-C motif chemokine receptor type 1 (CCR1), C-X-C Motif Chemokine Ligand 12 (CXCL12), Chemokine C-C motif ligand 12 (CCL12), C-C motif chemokine receptor type 2 (CCR2) to the lung;

4) The role of epigenetic changes in fibroblasts;

5) The role of additional, potential therapeutic targets and strategies like Peroxisome proliferator-activated receptors $\alpha, \beta / \partial$, and $Y$; and,

6) The role of macrophages in disease stage-specific reactions and their secreted mediators like Transforming growth factor beta 1 (TGF- $\beta 1$ ) and Platelet-derived growth factor (PDGF) [4].

Lung fibrosis can occur and develop after viral infections. It can also develop after radiotherapy, exposure to chemotherapeutic drugs, or exposure to aerosolized environmental toxins [8-11]. Among these factors, Savale et al. [12] found the role of interferon in PH and PF to be the most important. Interferons are a large family of cytokines that correspond to a group of secreted proteins that participate as extracellular messengers in a wide variety of responses. These antiviral, antiproliferative, immune-modulatory, and developmental activities act to maintain homeostasis and in-host defense $[12,13]$.

Because almost all viral infections are triggered by interferon induction and/or action, interferons have important roles in innate immunity. Additionally, interferons are produced because of viral stimulations in any kind of cells; therefore, they were firstly identified because they can confer resistance to viral infections [13]. They provide rapid and broad protection against a variety of pathogens as components of the immune system. Interferons have three subfamilies of molecules: type I includes several subgroups such as IFN- $\alpha$ and IFN- $\beta$, type II corresponds to IFN-Y, and type III corresponds to IFN- $\lambda$. All these subtypes are likely to have arisen from a common ancestral gene, and they all have a common intracellular signaling pathway $[12,13]$.

Interferons have been recently identified as an important possible risk factor for $\mathrm{PH}$, after several reports of association of IFN- $\alpha$ [14-19],
IFN- $\beta[14,16,20-23]$, and experimental models [24-27] with PH. Some of these cases had reversible PH [28-30] and some cases had irreversible $\mathrm{PH}$ after exposure to interferons [31-33].

\section{Epstein-Barr virus}

It is uncommon that an EBV infection becomes complicated and leads to ILD, PF, or PH in infected patients with efficient immune systems. However, rare reports of parenchymal pulmonary involvement do exist. Hilar or mediastinal lymphadenopathy, pleural effusion, and interstitial pneumonitis are three types of pulmonary involvement that can occur with EBV infections [34-39]. The radiological, histological, and computed tomography $(\mathrm{CT})$ scan appearances of EBV-infected patients are reported to include multiple nodules (large and small), with a peribroncho-vascular and sub-pleural distribution involving the middle and lower lung zones [40, 41]. A recent study by Sheng et al. [42] examining the relationship between EBV infections and IPF in patients reported that EBV could play a key role in the pathogenesis of IPF.

Replication of EBV inside the alveolar cells (type II) can occur in adult cryptogenic fibrosing alveolitis. It is related to latent membrane protein 1, which is one of the EBV-associated proteins. Latent membrane protein 1 is expressed during the latent and replicating phases of EBV infection on the surface EBV infected cells which is likely similar to what is occurring in adult cryptogenic fibrosing alveolitis and it can become positive in the cuboidal epithelial cells of the lungs of patients suffering from IPF who have been given a poor prognosis [43-45]. Lymphocytic interstitial pneumonia in HIV negative/immunocompetent patients infected by EBV in childhood [46, 47] and in adulthood presented with progressive dyspnea and dry cough as reported recently by Prasoppokakorn et al. [48]. Latent membrane protein 1 can become apparent in patients with severe IPF, and in total IPF had been identified more frequently in EBV positive patients than in healthy control groups [49]. It was also reported that an EBV infection can increase the risk of lung cancer in IPF patients [50, 51]. In addition, the effects of EBV infections on tumorigenicity, metastasis, and TRAIL-sensitivity of non-small cell lung cancer were reported [52]. Malizia et al. also reported that TGF $\beta 1$ is induced by an EBV infection of epithelial cells, and an EBV lytic phase induction can increase apoptosis of alveolar epithelial cells [53].

\section{Cytomegalovirus}

Yonemaru et al. [54] reported that patients with IPF and collagen vascular disease-related interstitial pneumonitis, Cytomegalovirus (CMV), had elevated immunoglobulin $G$ and complement fixation titers. Because CMV immunoglobulin $M$ was negative in most of these patients, this elevation may indicate that the latent CMV infection is more prominent in IPF and collagen vascular disease-related interstitial pneumonitis [54].

An animal model study in mice shows that a CMV infection may result in PF through a mechanism of increasing TNF- $\alpha$ expression. Ganciclovir, which acts via blockage of murine CMV reactivation, may prevent abnormal TNF- $\alpha$ expression and, finally, pulmonary fibrosis. In this study, mice had considerable increases in IL-1 $\beta, \mathrm{KC}$, and MIP-2 mRNA expression; adding to TNF- $\alpha$ expression compared to controls. Image analysis showed that CMV-infected mice had significantly increases in PF compared to control groups 3 weeks after infection [55].

To estimate the amount of CMV genome replication in patients suffering from IPF, Dworniczak et al. [56] calculated CMV's DNA copy number in broncho-alveolar lavage cells, blood leukocytes, and serum of patients with IPF. A highly closed relationship between CMV infection and IPF was reported in these patients. A higher CMV DNA copy number in blood serum was observed in IPF patients than in controls $(\log 10=3.2$ vs. 2.0 , respectively). It was also reported that the prevalence of the CMV DNA positive subjects in the patient group (75\%) was the same as the control group (69\%). In both patient and control groups, the mean CMV DNA copy number in broncho-alveolar lavage cells was significantly higher than that in blood leukocytes $(\log 10=2.7$ vs. 1.2 for patients and 2.8 vs. 0.9 for controls, respectively) [56]. 
Tang et al [49] found CMV infection to be significantly more frequent in IPF patients than in control groups. They found that CMV infection in patients with familial IPF was more frequent than in patients with sporadic IPF, but the reasons for this difference were not reported [49]. In Sheng's [42] novel meta-analysis, the relationship between CMV infections and IPF in infected patients had been strongly demonstrated and it was also reported that viral infections could play a key role in the pathogenesis of IPF.

\section{Human herpes virus 8}

A diagnosis of HHV-8, which is Y-herpesvirus and known as Kaposi's sarcoma (KS) associated herpes virus, may lead to the development of additional diseases including a different form of KS (classical, endemic and HIV-1-associated KS), HIV-1-associated B-cell primary effusion lymphoma, and Castleman disease (CD) [57]. An association between CD, which is highly related to HHV-8, and PH has been reported [58], along with an increased level of TNF- $\beta$, IL- 1 and IL- 6 in the serum of patients with CD [59]. To find the relationship between HHV-8 and IPF, Tang et al. [49] showed that HHV-8 infection is more frequent in IPF patients than in controls and HHV-8 infections were also reported to be more frequent in patients with sporadic IPF than in patients with familial IPF.

Sheng's [42] meta-analysis studied the relationship between HHV-8 infections and IPF in infected patients and reported that viral infections could play a key role in the pathogenesis of IPF. HHV-8 is identified as an absolute factor in IPF, and was speculated by Tang et al. that lung tissue that had latent infection with herpesviruses (HHV-6, 7, 8) could act as a stimulus for inflammation in IPF [60]. Using a murine model study, the role of Y-herpesvirus was confirmed in the augmentation of $\mathrm{PF}$, and it was reported that upregulation of chemokines during viral infection (and subsequent recruitment of fibrocytes to the lung) likely contribute to augmentation of PF [61].

Vannella et al. [62] also used a murine model to determine whether a latent herpesvirus infection can augment PF, and they found that latent infection upregulates the expression of pro-inflammatory chemokines, TGF- $\beta 1$, and cysteinyl leukotrienes in alveolar epithelial cells. This study also showed that enhanced fibrosis is highly associated with the induction of pro-fibrotic factors and the recruitment of fibrocytes, which supports the hypothesis that $\gamma$-herpesviruses can serve as an initiating cofactor in the pathogenesis of PF [62]. Calabrese et al. [63] reported different mechanisms for the association between herpes viruses and IPF and PH. In their novel study, herpes virus infections resulted in the development of $\mathrm{PH}$ in IPF patients through the probable mechanism of increasing TGF- $\beta$ expression; in addition, the remodeled vessels were shown to have increased vessel cell proliferation in proximity to metaplastic epithelial cells and macrophages [63]. It should be noted that although the relationship between HHV-8 and IPF had been demonstrated, there are several studies that reported different results [45, 64-66].

\section{Adenovirus}

There is no current published study that proves that a persistent adenovirus infection can induce TGF- $\beta$ secretions from epithelial cells, which may result in the transition of epithelial-mesenchymal and induce development of IPF [67]. In fact, Partovian et al. [68] reported that adenovirus-mediated gene transfer improves endothelial function and attenuates development of $\mathrm{PH}$; this novel study reported that vascular remodeling in a rat model of hypoxic $\mathrm{PH}$ may have clinical implications regarding the treatment of $\mathrm{PH}$. Kuwano et al. [69] reported that adenovirus is unlikely to be etiologically involved in the pathogenesis of IPF or interstitial pneumonia associated with collagen vascular disease. More studies are needed to prove this hypothesis.

\section{Hepatitis $\mathrm{C}$ virus}

Hepatitis C Virus (HCV) has been reported as a factor in the development of PF in infected patients. Ferri et al. [70], demonstrated anti HCV antibodies and HCV viraemia, and a viral genome was also detected in peripheral lymphocytes and in lung biopsy specimens. This study hypothesized that HCV chronic infection could represent a trigger factor for interstitial lung fibrosis [70]. HCV infection is also implicated in cases of IPF; during follow-up, patients with IPF have a high possibility of dying from acute exacerbation due to IPF, demonstrating a need to provide a high level of care for these patients. Physicians must therefore be conscious of any degree of dry coughing and dyspnea in HCV-infected patients. Age, smoking, and liver cirrhosis are additional factors reported to enhance the development of IPF in HCV-positive patients [71].

A high prevalence of anti-HCV antibodies (serum antibodies against Cl00-3 antigen) in patients with IPF has been reported using the HCV. ELISA method in confirmed IPF patients. This can be interpreted in four ways: (i) HCV itself is a pathogen of IPF; (ii) antibodies recognizing some epitope that mimics Cl00-3 antigen of HCV are involved in the pathogenesis of IPF; (iii) the ELISA is detecting some antibodies against superoxide dismutase to which Cl00-3 antigen is fused as part of the recombinant DNA technology; or (iv) the high prevalence of HCV is accompanied by chance with IPF, and HCV does not play a role in IPF [72]. A study of Italian patients with IPF by Meliconi et al. [73] recorded increased prevalence (approximately 13\%) of HCV infection and viral replication, but the prevalence of anti-HCV antibodies did not differ from other lung diseases.

A broncho-alveolar lavage study in HCV infection by Aliannejad et al. [74] reported increased counts of lymphocytes and neutrophils in broncho-alveolar lavage fluid. This recent cohort study also reported that $\mathrm{HCV}$ infection is highly associated with nonspecific pulmonary inflammatory reactions that are not compatible with IPF, but that it can lead to $\mathrm{PF}$. Interferons are another important factor reported by these authors; interstitial pneumonia and sarcoidosis have been reported as welldocumented complications of IFN therapy [74].

In contrast, a recent study by Yin et al. [75] using an RNA-seq method rejected the role of HCV in acute exacerbations of IPF; although sporadic, low-level evidence of viral infections in the studied lung tissue specimens had been recorded, and a statistical difference for expression of any virus was not found.

\section{Torque-Teno (transfusion-transmitted) virus}

There is little published data about the association between Torque-Teno (Transfusion-Transmitted) Virus (TTV) and IPF. Bando et al. [76] used a semi-nested polymerase chain reaction to find an association between TTV and IPF augmentation in TTV-infected patients. It reported that TTV DNA was detected in $36.4 \%$ of IPF patients. Serum LDH is an isoenzyme in chronic coughing and it is producing during the inflammations including viral infections and it can be also induced by IL-8, prostaglandins (D2 and E2), and IFN- $\alpha$, and it is a biomarker in immune mediated respiratory inflammation and the serum lactate dehydrogenase level was also significantly higher in the IPF patients with a TTV infection than in those without. Half of patients in the TTV DNA-positive group died during the observation period, whereas only $28.6 \%$ of patients in the TTV DNA-negative group died. The 3-year survival rate was significantly lower in the TTV DNA-positive group than in the TTV DNA-negative group (58.3\% vs. $95.2 \%, P<0.02)$ and replicative intermediate forms of TTV DNA had been detected in the lung specimen from a TTV-infected IPF patient. The authors concluded that TTV infection can influence the disease activity and prognosis of IPF in infected patients [76].

Wootton et al. [77], used a highly sensitive, genomics-based discovery method to investigate the role of viral infection in a large, wellcharacterized cohort of patients with acute exacerbation of IPF. In their study, TTV infection was reported as more common in patients with acute exacerbation than in stable controls, but present in a similar percentage of acute lung injury controls. Deep sequencing of a subset of acute exacerbation cases confirmed the presence of TTV but did not identify additional viruses. Although they study showed the absolute association between TTV infection and IPF augmentation in TTV infected patient, they reported that most cases of acute exacerbation of IPF are not caused by viral infection [77].

\section{Human immunodeficiency virus}

There are several published studies related to the association between HIV and ILDs, IPF, PH, and IPF. HIV viral proteins including negative factor, glycoprotein 120 and Trans activator of transcription had been 
identified to induce pulmonary vascular pathology in HIV-associated PH and was explored by Cool et al. in 2011 [57]. A higher degree of pulmonary hypertension was reported by Pellicelli et al. [78] on persons living with HIV who suffered from primary PH than HIV negative patients with primary $\mathrm{PH}$. Cytokine-related stimulation and proliferation of endothelium seems to be responsible for augmentation of $\mathrm{PH}$ associated with HIV infection in patients. PH in persons living with HIV had been suspected as causally related to high levels of cytokines present in their bodies, and high cytokine production levels is suspected to occur after host response to HIV infection [78]. Several studies have reported that persons living with HIV have a $>600$-fold higher incidence of PAH than does the general population, and one in 200 individuals diagnosed with AIDS develops PH [57, 78-80].

Humbert et al. [81] studied the association between HIV infection and $\mathrm{PH}$ via semi-quantitative polymerase chain reaction, in situ hybridization, and immunohistochemistry. It confirmed that interstitial perivascular cells expressing platelet-derived growth factor A-chain mRNA and protein could be detected by in situ hybridization and immunohistochemistry in persons living with HIV and suffered from $\mathrm{PH}$, respectively. Platelet-derived growth factor expression was reported as highly elevated in lung biopsies of patients with PH. They stated that growth factors, such as platelet-derived growth factor, may play an important absolute role in the initiation and/or progression of primary $\mathrm{PH}$ [81].

Two different roles, direct and indirect, were defined in a study by Pellicelli et al. [82] for HIV infection in generation/augmentation of $\mathrm{PH}$ in persons living with HIV. Direct effects of HIV and lymphokines released dependent effects in response to HIV infection are two direct roles defined by these authors. It has also been found that in the absence of evidence of direct pulmonary endothelium cell infection by HIV, an indirect role of the virus mediated by cytokines, including; endothelin-1 (ET-1), interleukin-1 $\beta$ (IL1 $\beta$ ), interleukin-6 (IL6), TNF $\alpha$ and PDGF, can be hypothesized [82, 83]. Figure 3 is extracted from Pellicelli et al. and shows how HIV can augment $\mathrm{PH}$ process via its effects on macrophages/ monocytes, platelets and lymphocytes to produce cytokines [82]. Figure 4 is also extracted from other authors work and shows how chronic hypoxia influence on pulmonary artery smooth muscle cells and induce chronic stimulation of $\alpha_{1}$-receptors [82].

\section{Severe acute respiratory syndrome}

Because COVID-19 and Severe Acute Respiratory Syndrome (SARS) are both from the coronavirus family of viruses, to predict and/or warn about COVID-19 post-infection pulmonary outcomes, it can be helpful to refer to studies from recent, similar pandemics, of SARS. Xie et al. [84] followed up on surviving SARS patients at least twice within 3 months after discharge. Patients underwent SARS-associated coronavirus (SARS-CoV) via IgG antibody testing, pulmonary function testing, and chest radiography and/or high-resolution CT (HRCT) examinations. Xie et al. [84] suggested that lung fibrotic changes caused by SARS disease occurred mostly in severely sick patients and may be selfrehabilitated. Patients had residual abnormalities on their chest x-rays and HRCT imaging mainly displaying interstitial thickening, groundglass opacification, bronchiectasis, and signs of volume loss [84].

Wang et al [85] also reported that 60 days after infection, SARS. infected patients had increased cellularity of bronchoalveolar lavage fluid with increased alveolar macrophages and CD8 cells. HRCT scores were reported as increased and correlated with T-cell numbers and their

\section{FIGURE 3}

HIV stimulates macrophages/monocytes, platelets and lymphocytes to produce cytokines.

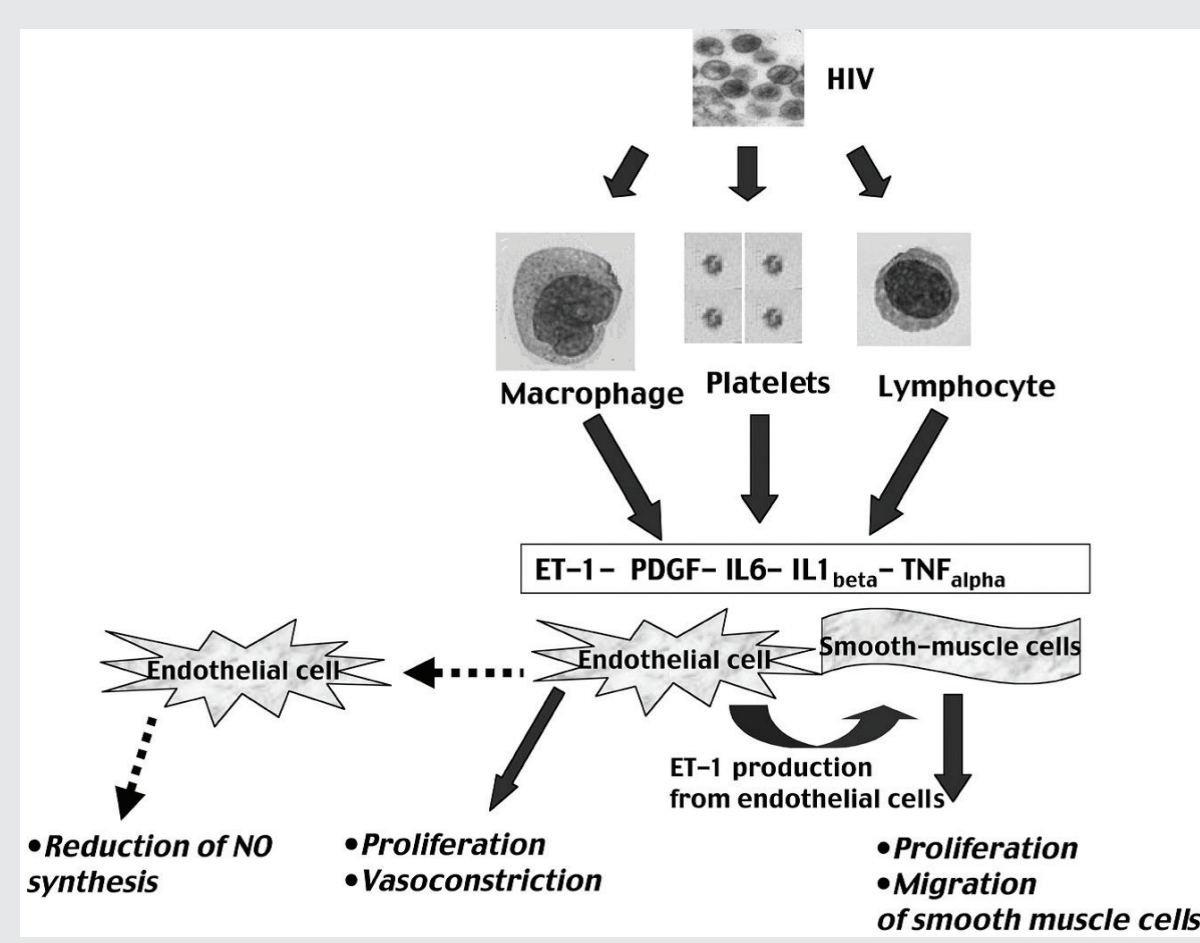

Note: Endothelin-1, interleukin-1 $\beta$, interleukin-6, and PDGF can interact with endothelial and smooth muscle cells. The final effects will be a reduction of vascular nitric oxide production, arterial vasoconstriction, proliferation and migration of smooth muscle cells, and an antiapoptotic effect [80]. Chronic hypoxia via chronic stimulation of a1-receptors of pulmonary vasculature and high a1-adrenoreceptors stimulation of pulmonary vessels in HIV positive patients can be also implicated in the pathogenesis of $\mathrm{PH}$ with typical pathological changes [80]. Figure 4 is also extracted from other authors work and shows how chronic hypoxia influence on pulmonary artery smooth muscle cells and induce chronic stimulation of a1-receptors [80]. 


\section{FIGURE 4}

Effect of chronic hypoxia on pulmonary artery smooth muscle cells.

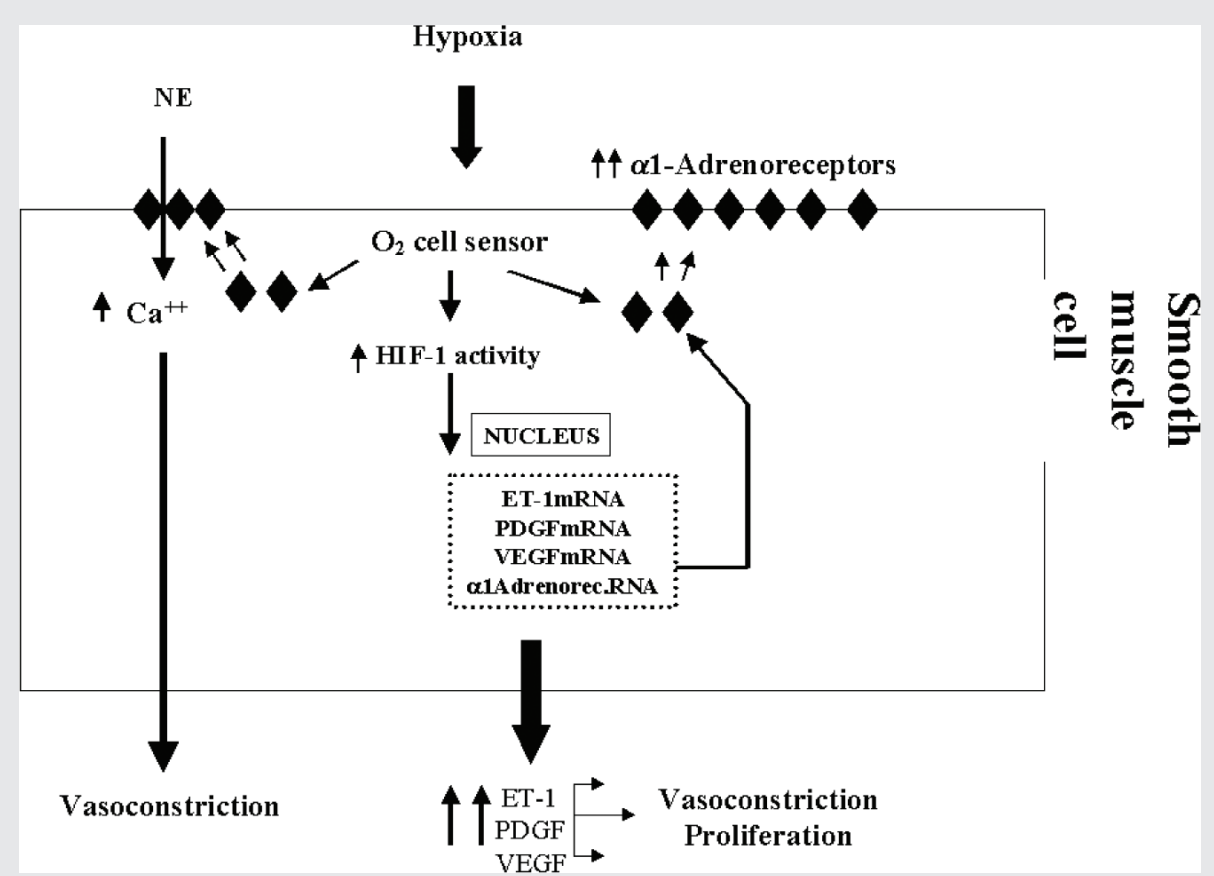

Note: Chronic hypoxia stimulates intracellular production of HIF-1 (hypoxia-inducible factor) which induces the transcription of various genes such as ET-1, PDGF, VEGF. Furthermore, HIF-1 enhances the production of a1-adrenoreceptors and a reduction of $\beta$-adrenoreceptors on the smooth muscle cell surface. Hypoxia can also increase NE (norepinephrine) plasmatic levels. NE, in the presence of an increased number of a1-adrenoreceptors, will induce an increase of intracellular free calcium levels and have a vasocostrictor effect. On the other hand, an increased production of cytokines will enhance vasoconstriction and produce cell proliferation [80].

subpopulations, and inversely with CD4/CD8 ratio. TNF- $\alpha$, IL-6, IL-8, RANTES and MCP-1 levels were increased. On day 90 after infection, HRCT scores improved significantly in most patients, with normalization of bronchoalveolar lavage fluid cell counts in half of patients with repeat bronchoscopy. Resolution of pneumonitis was delayed in some patients during SARS recovery and this may be associated with delayed clearance of SARS-CoV. Complete resolution may occur by 90 days or later after infection [85]. Nicholls et al [86] reported that within the first 10 days after SARS infection, the histological picture was that of acute phase diffuse alveolar damage (DAD) with a mixture of inflammatory infiltrate, edema and hyaline membrane formation. Desquamation of pneumocytes was prominent and consistent. After 10 days of illness, the picture changed to one of organizing DAD with increased fibrosis, squamous metaplasia and multinucleated giant cells [86].

\section{Middle East Respiratory Syndrome}

Like the SARS, Middle East Respiratory Syndrome (MERS) virus and COVID-19 are also from similar viral family and they may have same pathogenesis and post infection outcomes. There is less available data about MERS-CoV, but it had been reported that direct comparison of the follow-up chest radiographic findings with clinical data revealed several significant differences between patients with evidence of lung fibrosis and those without. Lung fibrosis, which had been detected on follow-up chest radiographs, is highly associated with a greater number of intensive care unit (ICU) admission days, older age, a higher chest radiographic score and higher peak lactate dehydrogenase level [87]. In other words, these are the underlying risk factors and/or predictors for developing lung fibrosis in MERS-CoV infected patients who recovered. It is understandable that lung fibrosis develops in patients who have been more severely infected with MERS-CoV (i.e., higher chest radiographic score) and who experience a longer infection period (i.e., greater number of ICU admission days). In addition, it was found that older patients with already aged lungs and decreased immune systems were not able to completely recover from MERS-CoV and were prone to develop viral-induced lung fibrosis $[87,88]$.

\section{COVID-19}

Coronavirus disease (COVID-19) is an international health concern that has patients reporting different common signs during the infection period including: fever (76.51\%), coughing $(58.39 \%)$, expectoration (32.21\%), dyspnea (1.34\%), muscle pain $(3.36 \%)$, headache $(8.72 \%)$, sore throat $(14.09 \%)$, nasal mucus $(3.36 \%)$, chest pain $(3.36 \%)$, chest tightness $(10.74 \%)$, chill $(14.09 \%)$, diarrhea $(7.38 \%)$, and nausea and vomiting $(1.34 \%)$ [7]. It has also been reported that COVID-19 may augment acute respiratory syndrome and acute pneumonia.

Radiological changes that have been reported in COVID-19 infected patients include pulmonary infiltration visible on CT scans, the pattern of multifocal peripheral ground-glass opacity, mixed ground-glass opacity, or consolidation with predominance in the lower lung. Presentation with extensive mixed opacity rather than ground-glass opacity and consolidation is highly indicative of 2019-nCoV infection when considering an interval between symptom onset and CT examination of 7 days [7]. It was also reported that COVID-19 pneumonia manifests on lung CT scans as bilateral, subpleural, ground-glass opacities with air bronchograms, ill-defined margins, and a slight predominance in the right lower lobe. Abnormal lung CT findings can be present even in asymptomatic patients, and lesions can rapidly evolve into a diffuse ground-glass opacity predominance or consolidation pattern within 1-3 weeks after onset 
of symptoms, peaking at around two weeks after onset [6]. These radiological appearances are closely associated with pulmonary parenchymal involvement. Because of the pulmonary parenchymal involvement in COVID-19-positive patients and with reference to the aforementioned radiological appearances, ILD, IPF, and PH can be considered as an important post-infection outcome for COVID-19 and/or COVID-19 can be considered as a possible augmenter for ILD, IPF, and PH.

Unfortunately, there is little current data about COVID-19 pathophysiology; however, it has been reported that although the host immune response is essential for the resolution of COVID-19 infection, it can also be crucial for the pathogenesis of major clinical manifestations of the disease [89]. The angiotensin-converting enzyme 2 (ACE2) has been identified as the host cell-surface receptor for SARS-CoV2 envelope spike glycoprotein $[89,90]$. ACE2 is a type I membrane protein expressed on cells in the kidney, heart, gastrointestinal tract, blood vessels, and, importantly, lung type 2 alveolar epithelial cells, which are particularly prone to viral infection $[89,91]$. Given that lung type 2 alveolar epithelial cells are involved in COVID-19 infections, it can be predicted that lung parenchyma will be strongly influenced by COVID-19 since it is confirmed in radiological and CT studies [7]. There are few histopathological studies on COVID-19 effects on the respiratory system at this time, and histopathological study in this area is highly recommended as a topic for future studies.

Deep venous thrombosis and its related outcomes, including alveolar damages, is also an important source of microscopic vascular damage in COVID-19 infected patients. In a recent autopsy study by Wichmann et al. [92] of patients who died due to COVID-19 infection, a high incidence of deep venous thrombosis (58\%) was reported. Pulmonary embolism was also reported as the direct cause of death in one-third of these patients. After histopathological studies, diffuse alveolar damage was demonstrated in $67 \%$ of patients [92].

\section{Limitations}

This narrative review study had some limitations such as: lack of available data for COVID-19 because it is a recent pandemic and lack of available published data for its pathogenesis and related post-infection outcomes. Additionally, some research was not available in our country (Iran). This was designed as a preliminary study in on April 2020 in the early days of the pandemic, so there were no available published data for its patterns, complications, and outcomes.

\section{CONCLUSION}

This review outlined the mechanisms of ILDs, IPF, and PH; the etiology and role of interferon in generation, induction and/or augmentation of ILDs; and looked at 10 viral infections including EBV, CMV, HHV-8, adenovirus, HCV, TTV, HIV, COVID-19, SARS-CoV, and MERS-CoV. This review finds that probable association between these viruses and ILDs, PF and PH is clear. ILDs can occur after COVID-19 viral infection and follow-up studies on COVID-19 infection healed patients is strongly recommended. A meta-analysis on pulmonary outcomes of pandemic corona viruses should be also considered for future studies.

\section{DISCLOSURES AND ACKNOWLEDGMENTS}

\section{Conflict of interest}

All authors have completed the ICMJE uniform disclosure form at www. icmje.org/coi_disclosure.pdf and declare: no financial relationships with any organizations that might have an interest in the submitted work in the previous 3 years; no other relationships or activities that could appear to have influenced the submitted work.

\section{Authors' contributions}

All authors contributed to the study. They prepared the manuscript for publication equally. All read and confirmed its publication.

\section{Ethical approval}

This review did not require institutional ethics approval.

\section{Funding/Support}

All the fees were covered by authors themselves and there was no financial support received from any real/legal person, organization, institute or etc.

\section{Acknowledgments}

Authors are grateful to all the persons who helped them to do this research.

\section{REFERENCES}

1. Thannickal VJ, Toews GB, White ES, Lynch Iii JP, Martinez FJ. Mechanisms of pulmonary fibrosis. Annu Rev Med 2004;55:395-417. doi: 10.1146/annurev.med.55.091902.103810.

2. Society AT. This joint statement of the American Thoracic Society (ATS), and the European Respiratory Society (ERS) was adopted by the ATS board of directors, June 2001 and by the ERS Executive Committee, June 2001. Am J Respir Crit Care Med 2002;165:277-304. doi: 10.1164/ ajrccm.165.2.ats01.

3. Gulati M. Diagnostic assessment of patients with interstitial lung disease. Prim Care Respir J 2011;20(2):120-7. doi: 10.4104/pcrj.2010.00079.

4. Wynn TA. Integrating mechanisms of pulmonary fibrosis. J Exp Med 2011;208(7):1339-50. doi: 10.1084/jem.20110551.

5. Selman M, King TE, Pardo A. Idiopathic pulmonary fibrosis: prevailing and evolving hypotheses about its pathogenesis and implications for therapy. Ann Intern Med 2001;134(2):136-51. doi: 10.7326/0003-4819. 134-2-200101160-00015.

6. Shi H, Han X, Jiang N, et al. Radiological findings from 81 patients with COVID-19 pneumonia in Wuhan, China: a descriptive study. Lancet Infect Dis 2020

7. Yang W, Cao Q, Qin L, et al. Clinical characteristics and imaging manifestations of the 2019 novel coronavirus disease (COVID-19): a multi-center study in Wenzhou city, Zhejiang, China. J Infect 2020. doi: 10.1016/j. jinf.2020.02.016.

8. Denham JW, Hauer-Jensen M. The radiotherapeutic injury - a complex "wound". Radiother Oncolo 2002;63(2):129-45.

9. Fubini B, Hubbard A. Reactive oxygen species (ROS) and reactive nitrogen species (RNS) generation by silica in inflammation and fibrosis. Free Radic Biol Med 2003;34(12):1507-16. doi: 10.1016/S0891-5849 (03)00149-7.

10. Kelly BG, Lok SS, Hasleton PS, Egan JJ, Stewart JP. A rearranged form of Epstein-Barr virus DNA is associated with idiopathic pulmonary fibrosis. Am J Respir Crit Care Med 2002;166(4):510-3.

11. Chen J, Stubbe J. Bleomycins: towards better therapeutics. Nat Rev Cancer 2005;5(2):102-12. doi: 10.1038/nrc1547.

12. Savale L, Chaumais M-C, O'Connell C, Humbert M, Sitbon O. Interferon-induced pulmonary hypertension: an update. Curr Opin Pulm Med 2016;22(5):415-20.

13. Ott TL, Ealy AD. Interferons. Encyclopedia of Reproduction: Elsevier; 2018. p. 412-6.

14. Savale L, Sattler C, Günther S, et al. Pulmonary arterial hypertension in patients treated with interferon. Eur Respir J 2014;44(6):1627-34. doi: 10.1183/09031936.00057914.

15. Fruehauf S, Steiger S, Topaly J, Ho A. Pulmonary artery hypertension during interferon- $\alpha$ therapy for chronic myelogenous leukemia. Ann Hematol 2001;80(5):308-10.

16. Antoniou KM, Ferdoutsis E, Bouros D. Interferons and their application in the diseases of the lung. Chest 2003;123(1):209-16. doi: 10.1378/ chest.123.1.209.

17. Renard S, Borentain P, Salaun E, et al. Severe pulmonary arterial hypertension in patients treated for hepatitis $\mathrm{C}$ with sofosbuvir. Chest 2016;149(3):e69-73

18. Savale L, Gunther S, Chaumais MC, et al. Pulmonary arterial hypertension in patients treated with interferon. Eur Respiratory Soc 2013.

19. Tsuchiya H, Kioka H, Ozu K, et al. Interferon therapy exacerbated pulmonary hypertension in a patient with hepatitis $\mathrm{C}$ virus infection: pathogenic interplay among multiple risk factors. Intern Med 2017;56(9):1061-5. doi: 10.2169/internalmedicine.56.7822.

20. Caravita S, Secchi MB, Wu SC, Pierini S, Paggi A. Sildenafil therapy for interferon- $\beta$-1a-induced pulmonary arterial hypertension: a case report. Cardiology 2011;120(4):187-9.

21. Prella M, Yerly P, Nicod LP, Aubert J-D. Pulmonary arterial hypertension in patients treated with interferon. Eur Respir J 2015;46(6):1849-51. doi: $10.1183 / 13993003.02327-2014$. 
22. Piroddi IMG, Barlascini C, Nicolini A. Severe respiratory failure due to interferon beta-related pulmonary hypertension. Am J Ther 2016;23(5):e1275-6.

23. Demerouti E, Karyofyllis P, Athanassopoulos G, et al. Pulmonary arterial hypertension associated with interferon-beta treatment for multiple sclerosis. Case report and literature review. Mult Scler Relat Disord 2019;28:273-5.

24. Michael Z, Christou H, Hudalla H, et al. Acetazolamide modulates pulmonary inflammation and ameliorates severe experimental pulmonary hypertension. Am Acad Pediatr 2018.

25. Sugimoto K, Nakazato K, Sato A, et al. Autoimmune disease mouse model exhibits pulmonary arterial hypertension. PLoS One 2017;12(9):e0184990. doi: 10.1371/journal.pone.0184990.

26. Bauer EM, Zheng H, Lotze MT, Bauer PM. Recombinant human interferon alpha $2 \mathrm{~b}$ prevents and reverses experimental pulmonary hypertension. PLoS One 2014;9(5):e96720.

27. Miyata M, Sakuma F, Yoshimura A, Ishikawa H, Nishimaki T, Kasukawa R. Pulmonary hypertension in rats 2. Int Archiv Allergy Immunol 1995; 108(3):287-91.

28. Gibbons E, Promislow S, Davies R, et al. Reversible pulmonary arterial hypertension associated with interferon-beta treatment for multiple sclerosis. Can Respir J 2015;22(5):263-5. doi: 10.1155/2015/181535.

29. Baghizadeh S, Sahraian MA, Ghahari M. Reversible pulmonary artery hypertension in association with interferon-beta therapy for multiple sclerosis. Iran J Neurol 2016;15(1):54.

30. Mattei D, Feola M, Orzan F, Mordini N, Rapezzi D, Gallamini A. Reversible dasatinib-induced pulmonary arterial hypertension and right ventricle failure in a previously allografted CML patient. Bone Marrow Transplant 2009;43(12):967-8.

31. Dhillon S, Kaker A, Dosanjh A, Japra D, VanThiel DH. Irreversible pulmonary hypertension associated with the use of interferon alpha for chronic hepatitis C. Dig Dis Sci 2010;55(6):1785-90.

32. Jochmann N, Kiecker F, Borges AC, et al. Long-term therapy of interferon-alpha induced pulmonary arterial hypertension with different PDE-5 inhibitors: a case report. Cardiovasc Ultrasound 2005;3(1):26.

33. Dhillon S, Baluch M, George M, Van Thiel DH. Irreversible pulmonary artery hypertension during interferon-alpha therapy for $\mathrm{HCV}$ infection: a case report. Am J Gastroenterol 2003;98(s9):S179. doi: 10.1016/ S0002-9270(03)01305-4.

34. Andiman WA, McCarthy P, Markowitz RI, Cormier D, Horstmann DM. Clinical, virologic, and serologic evidence of Epstein-Barr virus infection in association with childhood pneumonia. J Pediatr 1981;99(6):880-6.

35. Fermaglich DR. Pulmonary involvement in infectious mononucleosis. J Pediatr 1975;86(1):93-5.

36. Pfleger A, Eber E, Popper H, Zach M. Chronic interstitial lung disease due to Epstein-Barr virus infection in two infants. Eur Respir J 2000;15(4):803-6.

37. Schmitz H, Volz D, Krainick-Riechert C, Scherer M. Acute Epstein-Barr virus infections in children. Med Microbiol Immunol 1972;158(1):58-63.

38. Schmitz H, Scherer M. IgM antibodies to Epstein-Barr virus in infectious mononucleosis. Archiv für die gesamte Virusforschung 1972;37(4): $332-9$.

39. Veal C, Carr M, Briggs Jr D. Diffuse pneumonia and acute respiratory failure due to infectious mononucleosis in a middle-aged adult. Am Rev Respir Dis 1990;141(2):502-4.

40. Collins J, Müller N, Leung AN, et al. Epstein-Barr-virus-associated lymphoproliferative disease of the lung: CT and histologic findings. Radiology 1998;208(3):749-59. doi: 10.1148/radiology.208.3.9722856.

41. Hare S, Souza C, Bain G, et al. The radiological spectrum of pulmonary lymphoproliferative disease. Br J Radiol 2012;85(1015):848-64.

42. Sheng G, Chen P, Wei Y, et al. Viral infection increases the risk of idiopathic pulmonary fibrosis: a meta-analysis. Chest 2019.

43. Marzouk K, Corate L, Saleh S, Sharma OP. Epstein-Barr-virus-induced interstitial lung disease. Curr Opin Pulm Med 2005;11(5):456-60. doi: 10.1097/01.mcp.0000176678.38539.9a.

44. Jafarian AH, Roshan NM, Ayatollahi H, Omidi AA, Ghaznavi M, Gharib M. Epstein-Barr virus and human Herpesvirus 8 in idiopathic pulmonary fibrosis. Iran J Pathol 2020;15(1):30.

45. Zamò A, Poletti V, Reghellin D, et al. HHV-8 and EBV are not commonly found in idiopathic pulmonary fibrosis. Sarcoidosis Vasc Diffuse Lung Dis 2005;22(2):123-8.

46. Mueller GA, Pickoff AS. Pediatric lymphocytic interstitial pneumonitis in an HIV-negative child with pulmonary Epstein-Barr virus infection. Pediatr Pulmonol 2003;36(5):447-9. doi: 10.1002/ppul.10341.
47. Ankermann T, Claviez A, Wagner HJ, Krams M, Riedel F. Chronic interstitial lung disease with lung fibrosis in a girl: uncommon sequelae of Epstein-Barr virus infection. Pediatr Pulmonol 2003;35(3):234-8.

48. Prasoppokakorn T, Assanasen T, Chantranuwat P, Suankratay C. EBVassociated lymphoid interstitial pneumonia in IBD patient: case report and literature review. Respir Med Case Rep 2020;30:101059.

49. Tang Y-W, Johnson JE, Browning PJ, et al. Herpesvirus DNA is consistently detected in lungs of patients with idiopathic pulmonary fibrosis. J Clin Microbiol 2003;41(6):2633-40.

50. Carpagnano GE, Lacedonia D, Natalicchio MI, et al. Viral colonization in exhaled breath condensate of lung cancer patients: possible role of EBV and CMV. Clin Respir J 2018;12(2):418-24.

51. Iasella CJ, Winters SA, Kois A, et al. Idiopathic pulmonary fibrosis lung transplant recipients are at increased risk for EBV-associated post-transplant lymphoproliferative disorder and worse survival. Am J Transplant 2019. doi: 10.1111/ajt.15756.

52. Wang L, Liu Lf, Zhou L, Liao F, Wang J. Effects of ebv-miR-BART7 on tumorigenicity, metastasis, and TRAIL sensitivity of non-small cell lung cancer. J Cell Biochem 2019;120(6):10057-68.

53. Malizia AP, Keating DT, Smith SM, Walls D, Doran PP, Egan JJ. Alveolar epithelial cell injury with Epstein-Barr virus upregulates TGF $\beta 1$ expression. Am J Physiol Lung Cell Mol Physiol 2008;295(3):L451-60. doi: 10.1152/ajplung.00376.2007.

54. Yonemaru M, Kasuga I, Kusumoto H, et al. Elevation of antibodies to cytomegalovirus and other herpes viruses in pulmonary fibrosis. Eur Respir J 1997;10(9):2040-5.

55. Cook CH, Zhang Y, Sedmak DD, Martin LC, Jewell S, Ferguson RM. Pulmonary cytomegalovirus reactivation causes pathology in immunocompetent mice. Crit Care Med 2006;34(3):842. doi: 10.1097/01. CCM.0000201876.11059.05.

56. Dworniczak S, Ziora D, Kapral M, et al. Human cytomegalovirus DNA level in patients with idiopathic pulmonary fibrosis. J Physiol Pharmacol 2004;55(Suppl 3):67-75.

57. Cool CD, Voelkel NF, Bull T. Viral infection and pulmonary hypertension: is there an association? Expert Rev Respir Med 2011;5(2):207-16.

58. Bull T, Cool C, Serls A, et al. Primary pulmonary hypertension, Castleman's disease and human herpesvirus-8. Eur Respir J 2003;22(3):403-7.

59. Winter SS, Howard TA, Ritchey AK, Keller FG, Ware RE. Elevated levels of tumor necrosis factor-beta, gamma-interferon, and IL-6 mRNA in Castleman's disease. Med Pediatr Oncol 1996;26(1):48-53.

60. Tang Y-W, Johnson J, Cruz-Gervis R, et al. Increased detection of herpesvirus DNA in idiopathic pulmonary fibrosis. Chest 2001;120(1):S74-5. doi: 10.1016/S0012-3692(15)38729-8.

61. McMillan TR, Moore BB, Weinberg JB, et al. Exacerbation of established pulmonary fibrosis in a murine model by gammaherpesvirus. Am J Respir Crit Care Med 2008;177(7):771-80.

62. Vannella KM, Luckhardt TR, Wilke CA, van Dyk LF, Toews GB, Moore BB. Latent herpesvirus infection augments experimental pulmonary fibrosis. Am J Respir Crit Care Med 2010;181(5):465-77.

63. Calabrese F, Kipar A, Lunardi F, et al. Herpes virus infection is associated with vascular remodeling and pulmonary hypertension in idiopathic pulmonary fibrosis. PLoS One 2013;8(2):e55715. doi: 10.1371/ journal.pone.0055715.

64. Henke-Gendo C, Mengel M, Hoeper MM, Alkharsah K, Schulz TF. Absence of Kaposi's sarcoma-associated herpesvirus in patients with pulmonary arterial hypertension. Am J Respir Crit Care Med 2005;172(12):1581-5.

65. Bendayan D, Sarid R, Cohen A, Shitrit D, Shechtman I, Kramer M. Absence of human herpesvirus 8 DNA sequences in lung biopsies from Israeli patients with pulmonary arterial hypertension. Respiration 2008;75(2):155-7.

66. Katano H, Ito K, Shibuya K, Saji T, Sato Y, Sata T. Lack of human herpesvirus 8 infection in lungs of Japanese patients with primary pulmonary hypertension. J Infect Dis 2005;191(5):743-5.

67. Hayashi S, Hogg JC. Adenovirus infections and lung disease. Curr Opin Pharmacol 2007;7(3):237-43. doi: 10.1016/j.coph.2006.11.014.

68. Partovian C, Adnot S, Raffestin B, et al. Adenovirus-mediated lung vascular endothelial growth factor overexpression protects against hypoxic pulmonary hypertension in rats. Am J Respir Cell Mol Biol 2000;23(6):762-71.

69. Kuwano K, Nomoto Y, Kunitake R, et al. Detection of adenovirus E1A DNA in pulmonary fibrosis using nested polymerase chain reaction. Eur Respir J 1997;10(7):1445-9. 
70. Ferri C, La Civita L, Fazzi P, et al. Interstitial lung fibrosis and rheumatic disorders in patients with hepatitis $\mathrm{C}$ virus infection. $\mathrm{Br} \mathrm{J}$ Rheumatol 1997;36(3):360-5.

71. Arase Y, Suzuki F, Suzuki Y, et al. Hepatitis C virus enhances incidence of idiopathic pulmonary fibrosis. World J Gastroenterol 2008;14(38):5880. doi: $10.3748 /$ wjg.14.5880.

72. Ueda T, Ohta K, Suzuki N, et al. Idiopathic Pulmonary Fibrosis and High Prevalence of Serum Antibodies to Hepatitis C Virus1 • 2. Am Rev Respir Dis 1992;1(148):268.

73. Meliconi R, Andreone P, Fasano L, et al. Incidence of hepatitis C virus infection in Italian patients with idiopathic pulmonary fibrosis. Thorax 1996;51(3):315-7.

74. Aliannejad R, Ghanei M. Hepatitis C and pulmonary fibrosis. Hepat Mon 2011;11(2):71.

75. Yin Q, Strong MJ, Zhuang Y, et al. Assessment of viral RNA in idiopathic pulmonary fibrosis using RNA-seq. BMC Pulm Med 2020;20(1):1-12. doi: 10.1186/s12890-020-1114-1.

76. Bando M, Ohno S, Oshikawa K, Takahashi M, Okamoto H, Sugiyama Y. Infection of TT virus in patients with idiopathic pulmonary fibrosis. Respir Med 2001;95(12):935-42.

77. Wootton SC, Kim DS, Kondoh Y, et al. Viral infection in acute exacerbation of idiopathic pulmonary fibrosis. Am J Respir Crit Care Med 2011;183(12):1698-702.

78. Pellicelli AM, Barbaro G, Palmieri F, et al. Primary pulmonary hypertension in HIV patients: a systematic review. Angiology 2001;52(1):31-41.

79. Hughes JD, Rubin LJ. Primary pulmonary hypertension. An analysis of 28 cases and a review of the literature. Medicine 1986;65(1):56-72. doi: 10.1097/00005792-198601000-00004.

80. Speich R, Jenni R, Opravil M, Pfab M, Russi EW. Primary pulmonary hypertension in HIV infection. Chest 1991;100(5):1268-71.

81. Humbert M, Monti G, Fartoukh M, et al. Platelet-derived growth factor expression in primary pulmonary hypertension: comparison of HIV seropositive and HIV seronegative patients. Eur Respir J 1998;11(3):554-9.
82. Pellicelli AM, Palmieri F, Cicalini S, Petrosillo N. Pathogenesis of HIV-related pulmonary hypertension. Ann N Y Acad Sci 2001;946(1): $82-94$.

83. Mette SA, Palevsky HI, Pietra GG, et al. Primary pulmonary hypertension in association with human immunodeficiency virus infection. Am Rev Respir Dis 1992;145:1196-200. doi: 10.1164/ajrccm/ 145.5.1196.

84. Xie L, Liu Y, Xiao Y, et al. Follow-up study on pulmonary function and lung radiographic changes in rehabilitating severe acute respiratory syndrome patients after discharge. Chest 2005;127(6):2119-24.

85. Wang C-H, Liu C-Y, Wan Y-L, et al. Persistence of lung inflammation and lung cytokines with high-resolution CT abnormalities during recovery from SARS. Respir Res 2005;6(1):42.

86. Nicholls J, Dong XP, Jiang G, Peiris M. SARS: clinical virology and pathogenesis. Respirology 2003;8:S6-8.

87. Das KM, Lee EY, Singh R, et al. Follow-up chest radiographic findings in patients with MERS-CoV after recovery. Indian J Radiol Imaging 2017;27(3):342. doi: 10.4103/ijri.IJRI_469_16.

88. Naik PK, Moore BB. Viral infection and aging as cofactors for the development of pulmonary fibrosis. Expert Rev Respir Med 2010;4(6):759-71.

89. Favalli EG, Ingegnoli F, De Lucia O, Cincinelli G, Cimaz R, Caporali R. COVID-19 infection and rheumatoid arthritis: Faraway, so close! Autoimmun Rev 2020;19:102523. doi: 10.1016/j.autrev.2020.102523.

90. Hoffmann M, Kleine-Weber H, Schroeder S, et al. SARS-CoV-2 cell entry depends on ACE2 and TMPRSS2 and is blocked by a clinically proven protease inhibitor. Cell 2020.

91. Zhao Y, Zhao Z, Wang Y, Zhou Y, Ma Y, Zuo W. Single-cell RNA expression profiling of ACE2, the putative receptor of Wuhan 2019-nCov. BioRxiv 2020. doi: 10.1101/2020.01.26.919985.

92. Wichmann D, Sperhake J-P, Lütgehetmann M, et al. Autopsy findings and venous thromboembolism in patients with COVID-19: a prospective cohort study. Ann Intern Med 2020. doi: 10.7326/M20-2003. 